\title{
Metabolitos secundarios y Actividad bactericida de Calceolaria scapiflora (Calceolariaceae) y Semillas de Persea americana (Lauraceae)
}

\section{Secondary metabolites and Bactericidal activity of Calceolaria scapiflora (Calceolariaceae) and seeds of Persea americana (Lauraceae)}

\author{
Martha N. Mostajo-Zavaleta ${ }^{*}$, Fructuosa De La Torre-Mayorga ${ }^{1}+$ Richard Tito $^{1,2}$ \\ ${ }^{1}$ Escuela profesional de Biología, Facultad de Ciencias Universidad Nacional De San Antonio Abad del Cusco, \\ Av. de la Cultura, 733 Cusco, Perú. \\ ${ }^{2}$ Instituto de Biología, Universidade Federal de Uberländia, Av. Para 1720,38405, Uberländia, MG, Brasil. \\ *Autor corresponsal: Martha N. Mostajo-Zavaleta, martha.mostajo@unsaac.edu.pe
}

\begin{abstract}
RESUMEN
En la presente investigación se determinó los metabolitos secundarios, la citotoxicidad y la actividad bactericida, del extracto acuoso de Calceolaria scapiflora (madre zapatilla) muestreada en la comunidad Huaccoto - San Jerónimo-Cusco y pepa de Persea americana variedad fuerte (palta) en el distrito de Limatambo, Provincia de Anta- Cusco. Se preparó extracto acuoso al 5\% de la parte aérea (tallo, hojas y flores) de Calceolaria scapiflora y de pepa de Persea americana var. fuerte. Se realizó el tamizaje fitoquímico de los dos extractos, los metabolitos secundarios encontrados en los extractos acuosos de $C$. scapiflora y pepa de $P$. americana fueron: lactonas sesquiterpenicas, compuestos fenólicos, triterpenos y flavonoides. La determinación de citotoxicidad de los extractos acuosos se hizo a concentraciones de 10, 100 y $1000 \mu \mathrm{g} / \mathrm{ml}$., utilizando nauplios de A. salina, la concentración letal media se determinó con el método Probit. La dosis letal media del extracto acuoso de $C$. scapiflora fue de 276,658 ppm y 1519,398 ppm de pepa de palta. La actividad bactericida invitro, se realizó utilizando el método de difusión en agar, a concentraciones de los extractos acuosos de $12000 \mu \mathrm{g} / \mathrm{ml}$, $16600 \mu \mathrm{g} / \mathrm{ml} ; 19300 \mu \mathrm{g} / \mathrm{ml} ; 24200 \mu \mathrm{g} / \mathrm{ml} ; \mathrm{y}$ amikacina $30 \mathrm{mg}$ (testigo). El extracto acuoso de $C$. scapiflora tiene efecto bactericida sobre la cepa de Staphylococcus aureus ATCC 25902 con la concentración de 24 200ug/ml, generando un halo de inhibición de 22,8 mm, frente a la cepa de Escherichia coli ATCC 25901 que no presentó efecto bactericida.
\end{abstract}

Palabras Clave: Extracto acuoso, Calceolaria scapiflora, pepa de Persea americana, citotoxicidad, bactericida.

\begin{abstract}
In the present work, the secondary metabolites, cytotoxicity and bactericidal activity of the aqueous extract of Calceolaria scapiflora (slipper mother) sampled in the Huaccoto community - San Jerónimo-Cusco and pit of Persea americana strong variety (avocado) from the district of Limatambo, Province Anta- Cusco were determinated. A 5\% aqueous extract of the aerial part (stem, leaves and flowers) of Calceolaria scapiflora and Persea americana seed was prepared. The phytochemical screening of the two extracts was performed. The secondary metabolites found in the aqueous extracts of C. scapiflora and P. americana seed were: sesquiterpenic lactones, phenolic compounds, triterpenes and flavonoids. For the determination of cytotoxicity of the aqueous extracts at concentrations of 10,100 and $1000 \mu \mathrm{g} / \mathrm{ml}$., Nauplii of $A$. salina were used, the mean lethal concentration was determined with the Probit method, the mean lethal dose of the aqueous extract of $C$. scapiflora is $276,658 \mathrm{ppm}$ and $1519,398 \mathrm{ppm}$ of avocado seed. The in vitro bactericidal activity was carried out using the agar diffusion method, at concentrations of the aqueous extracts of $12000 \mu \mathrm{g} / \mathrm{ml}, 16600 \mu \mathrm{g} / \mathrm{ml} ; 19300 \mu \mathrm{g} / \mathrm{ml}$; $24200 \mu \mathrm{g} / \mathrm{ml}$; and amikacin $30 \mathrm{mg}$, the aqueous extract of C. scapiflora has a greater bactericidal effect on the Staphylococcus aureus ATCC 25902 strain with the concentration of $24,200 \mathrm{ug} / \mathrm{ml}$, generating an inhibition halo of $22.8 \mathrm{~mm}$, compared to the Escherichia coli strain ATCC 25901 did not show a bactericidal effect.
\end{abstract}

Key Words: Aqueous extract, Calceolaria scapiflora, pepa de Persea americana, cytotoxicity, bactericide.

\section{INTRODUCCIÓN}

La utilización de plantas medicinales es una práctica antigua y sirvió de base para la farmacología moderna. Los productos naturales, incluyendo plantas medicinales, son bastante valorados y utilizados en la actualidad (Farnsworth et al., 1985), principalmente por el bajo costo económico, accesibilidad y/o por causar mínimo efecto secundario en el cuerpo. De hecho, aproximadamente el $80 \%$ de la población mundial utiliza productos naturales con fines medicinales (Farnsworth et al., 1985). Los Andes tropicales es una de las regiones más biodiversas del mundo (Myers et al., 2000), entre los que se encuentra una gran diversidad de plantas medicinales (Brack, 1999). Un estudio reciente mostró que pobladores andinos, en especial de la región Cusco, actualmente utilizan gran diversidad de plantas medicinales para tratar diferentes dolencias (Huamantupa et al., 2011). La fitoterapia es de especial importancia principalmente para aquellas personas de bajos recursos económicos que difícilmente acceden a la medicina moderna que generalmente implica un costo económico elevado. Las plantas, además de proveer propiedades medicinales al consumidor, puede también afectar la salud humana por la presencia de toxinas en la composición fitoquímica de muchas especies (Shamsuddin et al., 2013). Esta es una de las razones importantes que motiva realizar estudios para determinar la acción farmacológica y la toxicidad de las plantas con potencial medicinal. El estudio de la presencia y actividad de metabolitos secundarios es ampliamente usado para este fin, ya que estas sustancias presentan una acción medicinal (Cotillo, 1990). Asimismo, la realización de bioensayos para determinar la actividad biológica y la toxicidad de las plantas sobre organismos modelo (p.ej. Artemia salina, Staphilococcus aureus, Escherichia coli) son recomendados y ampliamente usados (CMcLaughlin et al., 1993). De esta forma, estudios fitoquímicos y su consecuente prueba de actividad biológica puede proporcionar apoyo empírico 
para la farmacología moderna, además de poder auxiliar a fortalecer la fitoterapia popular.

En este estudio se realizó encuestas a la población de la ciudad de Cusco - Perú con el fin de saber el conocimiento actual sobre el uso de las estructuras aéreas (tallos, hojas y flores) de Calceolaria scapiflora y semillas de Persea america var. fuerte (palta). Asimismo, se realizó análisis fitoquímico y experimentos de bioensayo para determinar la eficiencia de la actividad antibacteriana y la citotoxicidad de los extractos acuosos de estas dos especies de planta. Para los experimentos del bioensayo se utilizó como modelo de estudio dos especies de bacterias (Escherichia coli y Staphylococcus aureus) que causan infección urinaria, una de las enfermedades más frecuentes que afectan al ser humano (Battilana, 1997). En los Estados Unidos de Norteamérica corresponde aproximadamente a 7 millones de consultas ambulatorias y 1 millón de atenciones por emergencia, por año; lo cual resulta en unas 100000 hospitalizaciones. Es probable que en el Perú sea algo similar; sin embargo, es difícil determinar su incidencia real debido a que no es una enfermedad reportable, el 86,6\% de infecciones urinarias corresponden al sexo femenino. (Astete, La Madrid et al. 2004). La citotoxicidad de los extractos de las plantas estudiadas se probó en nauplios de Artemia salina, bioensayo confiable y recomendado para correlacionar las propiedades citotóxicas y antitumorales de los extractos de plantas (CMc Laughlin et al., 1993).

Calceolaria scapiflora (Calceolariaceae) es una hierba anual silvestre, común que se distribuye de centro a sur del Ande peruano (3600-4700 m de altitud) (Puppo, 2006; Puppo, 2010). Persea americana (Lauraceae), por otro lado, es un árbol perenne ampliamente cultivado en más de medio centenar de países tropicales y subtropicales, incluyendo Perú (FAOSTAT, 2014). El fruto de la palta es comúnmente consumido y la semilla generalmente desechada, recurso que se podría aprovechar, por ejemplo, para tratar diversas enfermedades. El análisis fitoquímico de la semilla de aguacate muestra presencia de taninos y azucares reductores. Los taninos son sustancias con propiedades astringentes y antiinflamatorias, cumplen una función cicatrizante al acelerar la curación de las heridas y hemostática, al detener el sangrado (Jiménez \& Lazo, 2005). La cicatrización se produce por la formación de las costras al unirse a las proteínas con los taninos y crear un medio "seco" que impide el desarrollo de las bacterias. Al constreñir los vasos sanguíneos ayudan a la coagulación de la sangre. (Evans, 1984). Uno de los objetivos del presente estudio fue determinar su efecto bactericida, por la información recopilada en las encuestas realizadas, donde mencionaban que las semillas de palta hervida utilizaban para lavados vaginales en caso de cistitis.

En cuanto a Calceolaria scapiflora, no se ha encontrado trabajos publicados sobre efectos medicinales, teniendo como antecedentes para este estudio únicamente las encuestas realizadas a los pobladores de la comunidad Huaccoto - San Jerónimo-Cusco, son los que comercializan esta especie con fines medicinales.

\section{MÉTODOS}

\section{Colecta del material botánico y obtención de muestras}

La colecta de muestras de estructuras aéreas (tallos, hojas y flores) de $C$. scapiflora y semillas de $P$. americana se realizaron en dos localidades cercanas a la ciudad del Cusco, Perú (Cusco:

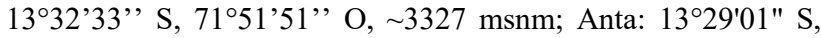
$\left.72^{\circ} 27^{\prime} 14 " \mathrm{O}, \sim 2542 \mathrm{msnm}\right)$. Estos lugares de colecta estaban libres de contaminación por residuos sólidos, desechos industriales u otros contaminantes que pueda haber influido en la composición fitoquímica. En los meses de enero y febrero se colectaron estructuras aéreas (es decir, hojas, tallos y flores; en adelante llamado como "ramas") de 150 individuos de $C$. scapiflora. En el mismo periodo, también colectamos 20 semillas provenientes de 20 individuos de $P$. americana var.fuerte. Las muestras fueron colocadas dentro de bolsas de papel y transportadas al laboratorio. Las impurezas de todas las muestras colectadas fueron limpiadas con agua destilada y luego secadas a temperatura ambiente por 15 días en las instalaciones del Herbario Vargas CUZ de la Facultad de Ciencias Biológicas - Universidad Nacional de San Antonio Abad del Cusco (UNSAAC). El local del secado presenta bastante iluminación, ventilación y mínima presencia de polvo. Específicamente, sobre una bancada se colocaron una capa de papel kraf y encima del papel se esparcieron las muestras vegetales, removiendo estas cada 24 horas. Muestras secas se trituraron usando un molino de grano para semillas de palta y mortero manual para ramas secas de $C$. scapiflora. Después de la molienda, fueron tamizadas para obtener harina para cada especie por separado. La harina se dividió en dos porciones, una porción para realizar el análisis fitoquímico y la otra para la extracción acuosa de los compuestos bioactivos de las plantas estudiadas. Adicionalmente, tres muestras de $C$. scapiflora se montaron y etiquetaron para la identificación sistemática, identificación realizada mediante comparaciones de muestras con ejemplares existentes en el Herbario Vargas CUZ. Se garantizó la correcta identificación mediante el uso de la bibliografía especializada y consulta a los botánicos visitantes al herbario.

La extracción acuosa de las muestras se realizó en el laboratorio de análisis químico de la UNSAAC. Para obtener el extracto acuoso al $5 \%, 25 \mathrm{~g}$ de muestra molida se mezcló con 250 $\mathrm{ml}$ de agua destilada en un frasco Erlenmeyer de $1 \mathrm{~L}$. Esta solución se sometió a una temperatura de $80^{\circ} \mathrm{C}$ durante 20 minutos para obtener el extracto acuoso. Después de este tiempo, se filtró usando papel filtro (5 piezas). Utilizando esta muestra acuosa se realizaron dos tipos de ensayos: un ensayo para saber la actividad biológica del extracto acuoso sobre nauplios de Artemia salina (Artemiidae) y otra para probar el efecto antibacteriano del extracto acuoso sobre cepas de Staphylococcus aureus (Gram positiva) y Escherichia coli (Gram negativa).

\section{Análisis fitoquímico}

En 500 g de la muestra triturada se analizó la presencia de metabolitos secundarios en el laboratorio de la escuela profesional de Farmacia y Bioquímica (Centrofarma - Centro de Control Analítico) de la Universidad Nacional Mayor de San Marcos Lima. Se analizaron la presencia de 10 principales metabolitos secundarios (lactonas sesquiterpénicas, compuestos fenólicos, triterpenos y/o esteroides, flavonoides, alcaloides, taninos, saponinas, quinonas, principios astringentes y amargos, aceite esencial y aminoácidos libres) siguiendo los procedimientos estandarizados en la literatura (AOAC, 1990).

\section{Prueba de toxicidad}

Para esta prueba se utilizó nauplios de A. salina, ya que es ampliamente usado como modelo animal de estudio, para determinar la toxicidad de plantas (Parra et al., 2001, Carballo et al., 2002). Para realizar el experimento, primero fueron criados en laboratorio huevos de $A$. salina hasta la fase de nauplios. Con este fin, una cubeta de vidrio ( $35 \mathrm{~cm}$ de largo x $25 \mathrm{~cm}$ de altura) se 
dividió verticalmente en dos secciones iguales, donde un lado se oscureció con pintura negra y la otra se dejó iluminada con luz artificial (lámpara de luz incandescente de 50 watts). Esto se hizo porque para la eclosión de huevos es necesaria la oscuridad y los nauplios son fototróficos (Carballo et al., 2002, Shamsuddin et al., 2013). La división de la cubeta se realizó con un pedazo de tecnopor que presentaban pequeños agujeros, de modo que pueda permitir la migración de nauplios al lado iluminado de la cubeta. En el lado oscuro de la cubeta se agregó $0,1 \mathrm{~g}$ de huevos de $A$. salina por cada litro de solución salina al 3,8\% (es decir, $38 \mathrm{~g}$ de sal marina disuelto en un litro de agua) y se dejó a una temperatura de $27^{\circ} \mathrm{C}$ durante 72 horas, tiempo suficiente para la eclosión de huevos de A. salina (Gualdron \& López, 1994). Después de 48 horas de la instalación se observó que los huevos estaban eclosionando, razón por lo que se colocó alimento a base de alga marina seca (micrón) y se esperó hasta completar 72 h para obtener la eclosión de $90 \%$ de huevos.

Para conocer la actividad biológica de los extractos sobre nauplios de A. salina se disolvieron extracto acuoso de $C$. scapiflora y $P$. americana en solución salina al 3,8 \% para obtener concentraciones de 10,100 y $1000 \mu \mathrm{g} / \mathrm{ml}$. Los nauplios de $A$. salina fueron expuestos a cuatro tratamientos: (1) agua salada al $3,8 \%$ (control); solución salina al 3,8\% con una concentración de (2) 10 ; (3) $100 ;$ y (4) $1000 \mu \mathrm{g} / \mathrm{ml}$ de extracto acuoso de $C$. scapiflora o P. americana. Cada tratamiento tuvo tres repeticiones (tubos de ensayo). A cada tubo de ensayo conteniendo $5 \mathrm{ml} \mathrm{de}$ dilución de los respectivos tratamientos se transfirió 10 nauplios de A. salina con una micropiteta $(100 \mu \mathrm{l})$. A todos los tubos se adicionaron $3 \mathrm{mg}$ de micrón por cada $5 \mathrm{ml}$ de agua salada como alimento y fueron colocados aleatoriamente en una cámara con iluminación (lámpara de luz blanca incandescente de 50 watts) a una temperatura de $27^{\circ} \mathrm{C}$ durante 24 horas. Pasado este tiempo, se contabilizaron cuántos individuos continuaban vivos.

\section{Pruebas de actividad antibacteriana}

Se probó el efecto antibacteriano del extracto acuoso de $C$. scapiflora y semillas de $P$. americana en cepas ATCC de $S$. aureus y $E$. coli, mediante el método de difusión en agar. Estas bacterias son los principales causantes de infección urinaria (Luján et al. 2008). A partir de 3-5 colonias de cada especie de bacteria previamente cultivada por 18-24 horas se transfirió a un tubo que contenía $4-5 \mathrm{ml}$ de caldo tripticasa soya. El caldo de cultivo fue incubado a $35^{\circ} \mathrm{C}$ hasta que alcance la turbidez equivalente a 0,5 del estándar de McFarland (4-6 horas). La turbidez del cultivo fue ajustada con caldo estéril. La suspensión resultante contenía aproximadamente $1-2 \times 10^{8} \mathrm{UFC} \mathrm{ml}{ }^{-1}$. Luego, se comparó visualmente el tubo con el inóculo y el estándar de McFarland al 0,5 frente a una cartulina con fondo blanco y rayas negras de contraste (para verificar si el inoculo tenía aproximadamente la misma concentración del estándar de McFarland). Se agito la suspensión y se sumergió un hisopo de algodón estéril con el cual se inoculó en cinco placas con medio Mueller-Hinton de $4 \mathrm{~mm}$ de profundidad, dispersando homogéneamente hasta cubrir toda la superficie de la placa. En cada placa, se colocó cinco discos de papel filtro embebido con cuatro diferentes concentraciones del extracto acuoso. En otras palabras, cepas de bacterias fueron expuestas a cinco diferentes tratamientos: (1) $12000 \mu \mathrm{g} / \mathrm{ml}$ de extracto acuoso disuelto en agua destilada; (2) $16600 \mu \mathrm{g} / \mathrm{ml}$; (3) $19300 \mu \mathrm{g} / \mathrm{ml}$; (4) $24200 \mu \mathrm{g} / \mathrm{ml}$; y, finalmente, (5) amikacina $30 \mathrm{mg}$. Éste último es un antibiótico muy utilizada para tratar las infecciones urinarias (La Madrid. et al. 2004), debido a que presenta una susceptibilidad de 93,8 \% para los patógenos (Lujan et al., 2008). Usamos este antibiótico con el objetivo de comparar el potencial antibacteriano de los extractos. El empleo de los discos de papel de filtro para pruebas de sensibilidad está estandarizado y se correlaciona con la concentración mínima inhibitoria. Los discos fueron presionados firmemente para asegurar el contacto completo con la superficie del agar inoculado con las bacterias. En seguida, las placas fueron invertidas y se incubaron a $37^{\circ} \mathrm{C}$ por 24 horas. Pasado este tiempo fueron medidos los halos de inhibición con la ayuda de un vernier (Baley, 2005).

Para determinar el contenido de sólidos disueltos en el extracto se pesó $15 \mathrm{ml}$ de la muestra acuosa en una balanza analítica de 4 decimales de precisión, utilizando pesafiltros. Los pesafiltros $(\mathrm{N}=6)$ conteniendo las muestras de $15 \mathrm{ml}$ de extracto se secaron a $105{ }^{\circ} \mathrm{C}$ hasta obtener peso constante y luego nuevamente fue pesada para obtener el peso seco. Así, el contenido de sólidos totales de la muestra se obtuvo mediante la relación entre el peso seco y peso de muestra líquida (es decir, 15 $\mathrm{ml}$ ) en porcentaje.

\section{Análisis estadístico}

El efecto de las diferentes concentraciones del extracto acuoso de $C$. scapiflora y $P$. americana sobre la sobrevivencia de nauplios de A. salina se determinaron utilizando el análisis de varianza (ANOVA) de una vía. La concentración de extracto que provoca la muerte del $50 \%$ de los individuos (concentración letal media, CL50) de nauplios de A. salina se calculó mediante el análisis de Probit. Utilizando ANOVA de una vía se determinó la diferencia de los diámetros de halos de inhibición de $S$. aureus entre las diferentes concentraciones de los extractos acuosos probados y así inferir la posible actividad antibacteriana de $C$. scapiflora. Para comparaciones múltiples entre los tratamientos se utilizó la prueba de Tukey. Los supuestos para realizar análisis paramétricos se verificaron mediante la exploración de residuos. Los análisis se realizaron utilizando Systat v.10.2 (SPSS 2000).

\section{RESULTADOS}

\section{Encuesta etnobotánica}

Gran parte de las personas entrevistadas (81\%) afirmaron que conocen y usan las estructuras aéreas (tallo, hojas y flores) de Calceolaria scapiflora y semillas de Persea americana para tratar diferentes dolencias. Más específicamente, la población usuaria afirmó que $C$. scapiflora la utilizan para desinflamar la matriz (35 $\%$ ), amígdalas (20\%) y órganos del sistema urinario (45\%) afectadas por las infecciones urinarias o cistitis. Por otro lado, las semillas de palta utilizan para curar la disentería y procesos diarreicos, así como para lavados vaginales, como desinflamante en la cistitis en infusión. Además, aproximadamente $70 \%$ de los entrevistados manifestaron que las propiedades curativas de estas plantas la aprendieron de sus ancestros.

\section{Análisis fitoquímico}

Resultados del análisis fitoquímico de las estructuras aéreas (tallo, hoja y flor) de $C$. scapiflora y semillas de $P$. americana var. fuerte mostró la presencia de cuatro metabolitos importantes, se encontró cantidad abundante de compuestos fenólicos en $C$. scapiflora, mientras que en semillas de $P$. americana lactonas sesquiterpénicas y triterpenos/esteroides, en cantidad moderada flavonoides y lactonas sequiterpénicas en C. scapiflora y compuestos fenólicos en semillas de $P$. americana var. fuerte (Tabla 1). 
Tabla 1: Resultado del análisis fitoquímico cualitativo de las estructuras aéreas (tallo, hoja y flor) de Calceolaria scapiflora y semillas de Persea americana var. fuerte. (-) Ausencia, (+) presencia traza, (++) presencia moderada, (+++) presencia abundante.

\begin{tabular}{|l|l|c|c|}
\hline \multicolumn{1}{|c|}{ Metabolito } & \multicolumn{1}{|c|}{ Método de ensayo } & Calceolaria scapiflora & Persea americana \\
\hline Lactonas sesquiterpénicas & Baljet & + & ++ \\
\hline Compuestos fenólicos & De cloruro férrico & ++ & ++ \\
\hline Triterpenos/esteroides & Liebermannburchard & + & ++ \\
\hline Flavonoides & De Shinoda & + & + \\
\hline Alcaloides & Dragendorff Mayer Wagner & - & - \\
\hline Taninos & De gelatina & - & - \\
\hline Saponinas & De la espuma & - & - \\
\hline Quinonas & Bonrtrager & - & - \\
\hline Principios astringentes y amargos & Organoléptico & - & - \\
\hline Aceite esencial & Característico & - & - \\
\hline Aminoácidos libre & De Ninhidrina & - & - \\
\hline
\end{tabular}

\section{Pruebas de toxicidad}

El efecto del extracto acuoso de C. scapiflora sobre nauplios de A. salina mostró letalidad significativa en las tres concentraciones $(10,100$ y $1000 \mu \mathrm{g} / \mathrm{ml})$ probadas $\left(\mathrm{F}_{3,8}=65,9 ; P\right.$ $<0,001$; Fig. 1A). Sin embargo, la magnitud del efecto fue directamente proporcional a la concentración del extracto utilizado. Se produjo aproximadamente $27 \%$ de mortalidad cuando los nauplios de $A$. salina fueron expuestos a una concentración de $10 \mu \mathrm{g} / \mathrm{ml}$ de extracto de $C$. scapiflora, mientras que a una concentración de $1000 \mu \mathrm{g} / \mathrm{ml}$ la mortalidad se incrementó hasta $80 \%$ (Fig. 1A). El efecto del extracto acuoso de semillas de $P$. americana sobre nauplios de $A$. salina fue significativo $\left(\mathrm{F}_{3,8}=20,3 ; P<0,001\right.$; Fig. 1A; Fig. 1B), pero sólo se detectó cuando los nauplios fueron expuestos a una concentración de 100 y $1000 \mu \mathrm{g} / \mathrm{ml}$ (Fig. 1B). La mortalidad de nauplios de A. salina fue similar en estas dos concentraciones (100 y $1000 \mu \mathrm{g} / \mathrm{ml}$ ) del extracto (Fig. 1B).

En general, con la prueba de mortalidad se encontró que la concentración letal media (CL50) para el extracto acuoso de $C$. scapiflora fue de 276,7 $\mu \mathrm{g} / \mathrm{ml}$ (LC: 93,2 - 526,6 $\mu \mathrm{g} / \mathrm{ml}$ ) y para el extracto acuoso de semillas de $P$. americana fue de $1519,4 \mu \mathrm{g} / \mathrm{ml}$ (LC: 953,1 - 7163,3 $\mu \mathrm{g} / \mathrm{ml}$ ).

EL extracto acuoso de $C$. scapiflora presentó mayor cantidad de sólidos disueltos $(16,2 \mathrm{~g} / \mathrm{l})$ que el extracto de semilla de $P$. americana $(9,6 \mathrm{~g} / \mathrm{l})$. (Fig. 1)

\section{Pruebas de actividad antibacteriana}

Resultados en relación al potencial efecto tóxico del extracto acuoso de C. scapiflora sobre las cepas de $S$. aureus ATCC 25923 revelaron que existe un efecto bactericida $\left(\mathrm{F}_{4,20}=159,2 ; P<\right.$ $0,001)$ y que la formación de halos de inhibición (indicativo del efecto bactericida) varía dependiendo a las concentraciones ensayadas (Fig. 2). Los resultados indican la relación positiva entre el efecto bactericida y la concentración de los extractos. Inclusive, el extracto acuoso de $C$. scapiflora a una concentración de $24200 \mu \mathrm{g} / \mathrm{ml}$ causó halo de inhibición del crecimiento de $S$. aureus significativamente mayor (diferencia de $\sim 3 \mathrm{~mm}$ ) que el antibiótico de amplio espectro amikacina (Fig. 2). Por otro lado, en la cepa de Escherichia coli el extracto de C. scapiflora no causó ningún efecto significativo. Los halos de inhibición sólo se observaron cuando las cepas fueron expuestas al antibiótico amikacina. Similarmente, no se encontró ningún efecto antibacteriano del extracto acuoso de $P$. americana tanto en $S$. aureus como en E. coli. (Figura.2)

\section{DISCUSIÓN}

En este estudio mostramos que los pobladores andinos (Cusco, Perú) utilizan comúnmente las estructuras aéreas (tallos, hojas y flores) de Calceolaria scapiflora y semillas de Persea americana para tratar inflamaciones en el sistema urinario, respiratorio y digestivo. Mediante el análisis fitoquímico y pruebas de actividad biológica de los extractos de estas plantas mostramos apoyo empírico para este uso terapéutico tradicional. Reportamos por primera vez el uso medicinal, principios activos y actividad biológica de $C$. scapiflora, y reforzamos a la literatura sobre las propiedades medicinales de semillas de $P$. americana. La presencia de cuatro metabolitos secundarios (compuestos fenólicos, flavonoides, lactonas sesquiterpénicas y triterpernos/esteroides) tanto en C. scapiflora como en semillas de $P$. americana (Tabla 1), revelan el potencial uso medicinal de estas especies ampliamente utilizados por los pobladores andinos. Es bastante conocido que estos metabolitos secundarios presentan distintos principios activos. Los flavonoides son antioxidantes, antimicrobianos, agentes de desintoxicación y a dosis altas pueden causar efectos antiinflamatorios, antivirales o antialérgicos, protegiendo inclusive contra enfermedades cardiovasculares y cancerígenas (Martínez-Flórez et al., 2002, Cushnie \& Lamb, 2005, Saxena et al., 2013). Las lactonas sesquiterpénicas presentan actividad antiinflamatoria, anticancerígena y antimicrobiana (Lin et al., 2003). Compuestos fenólicos poseen una acción antioxidante y actúan como agentes de desintoxicación (Saxena et al., 2013). A los triterpenos/esteroides, por otro lado, se le atribuye propiedades antimicrobianas (Katerere et al., 2003).

La determinación de la toxicidad de Artemia salina se ha utilizado eficientemente para probar el potencial de la actividad biológica de extractos de plantas (p.ej., McLaughlin et al., 1993, Parra et al., 2001). El extracto acuoso de las dos especies de plantas estudiadas mostró toxicidad sobre nauplios de A. salina, aumentando la actividad positivamente con la concentración del extracto. Sin embargo, el nivel de letalidad dependió de la especie. 


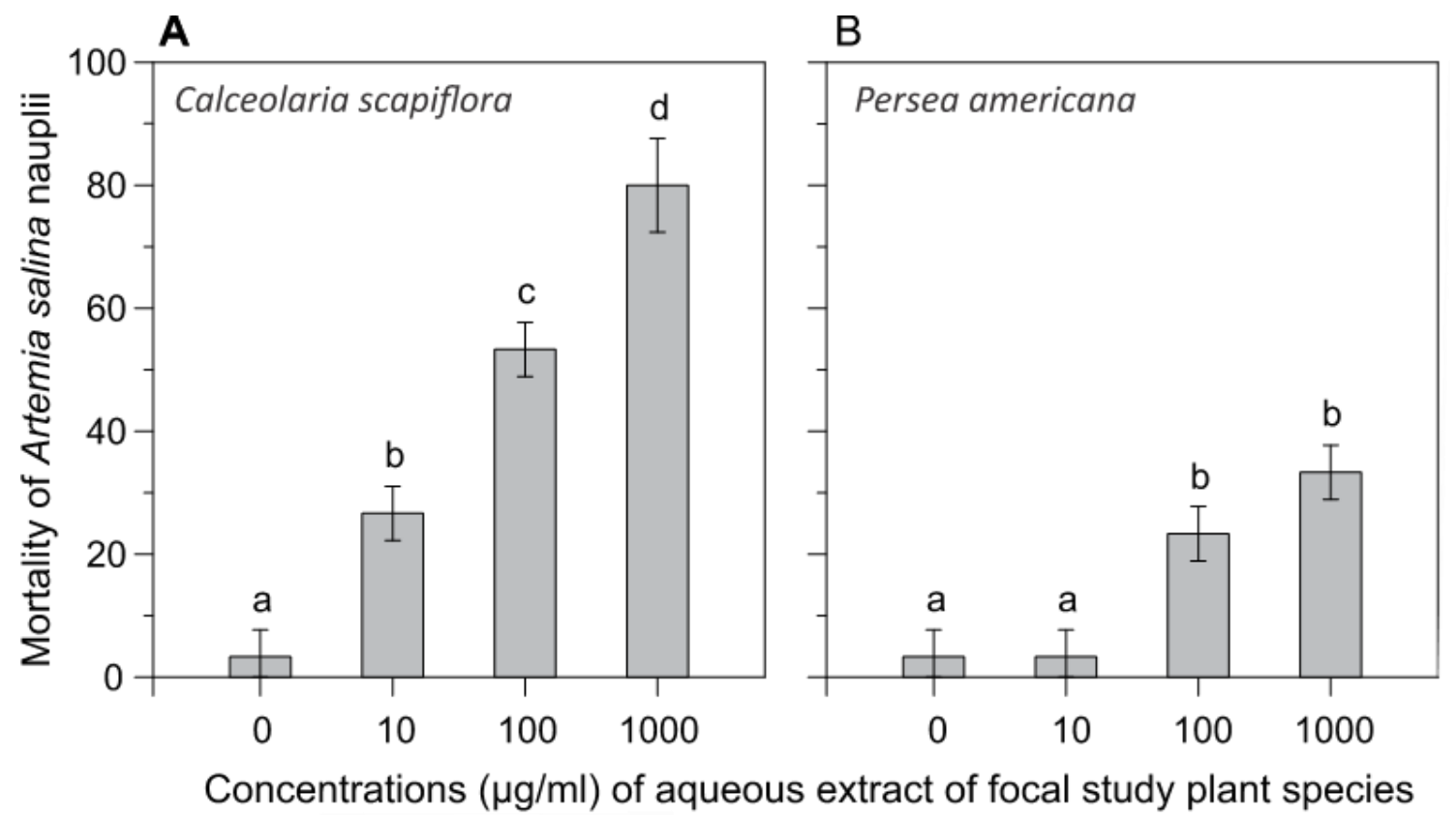

Figura 1. Porcentaje de mortalidad de nauplios de Artemia salina expuestas a diferentes consentraciones del extracto acuoso de estructuras aéreas (tallo, hojas y flores) de Calceolaria scapiflora y semillas de Persea americana var. fuerte. Letras diferentes sobre barras de error indican diferencia significativa $(P<0,05)$ entre los tratamientos.

A una concentración de $1000 \mu \mathrm{g} / \mathrm{ml}$ la letalidad causado por el extracto de C. scapiflora fue más que el doble de lo que causó el extracto de semillas de $P$. americana. Por tanto, una actividad más destacada (CL50 276,7) mostró el extracto acuoso de $C$. scapiflora en comparación al extracto de $P$. americana (CL50 1519,4) (Fig.01). La presencia de los mismos metabolitos en ambas especies de plantas sugiere que la efectividad de la actividad biológica puede estar relacionada a la diferencia en proporción de los compuestos que contiene cada extracto. El análisis fitoquímico mostró que extractos de $C$. scapiflora contienen compuestos fenólicos en cantidad abundante y flavonoides en cantidad moderada, en cambio el extracto de $P$. americana contiene estos metabolitos en cantidades moderada y traza respectivamente. Mayor cantidad de sólidos disueltos encontrado en el extracto de C. scapiflora $(16.2 \mathrm{~g} / \mathrm{l})$ también apoya esta idea.

El extracto acuoso de C. scapiflora indujo inhibición de crecimiento de Staphylococus aureus, pero la inhibición no ocurrió en Eschiricia coli, lo que demuestra la capacidad bactericida de este extracto sobre bacterias gram positivas, pero no en bacterias gram negativas. La efectividad bactericida del extracto de $C$. scapiflora sobre $S$. aureus fue desde moderada a alta, teniendo una relación positiva con el aumento de la concentración del extracto. Sorprendentemente, a una concentración de $24200 \mu \mathrm{g} / \mathrm{ml}$ presentó actividad bactericida incluso superior a al antibiótico amikacina comúnmente utilizado para tratar infecciones urinarias (Fig.2).

Esta actividad bactericida del extracto de C. scapiflora probablemente se debe a la abundante presencia de compuestos fenólicos y moderada cantidad de lactonas sesquiterpénicas y flavonoides.

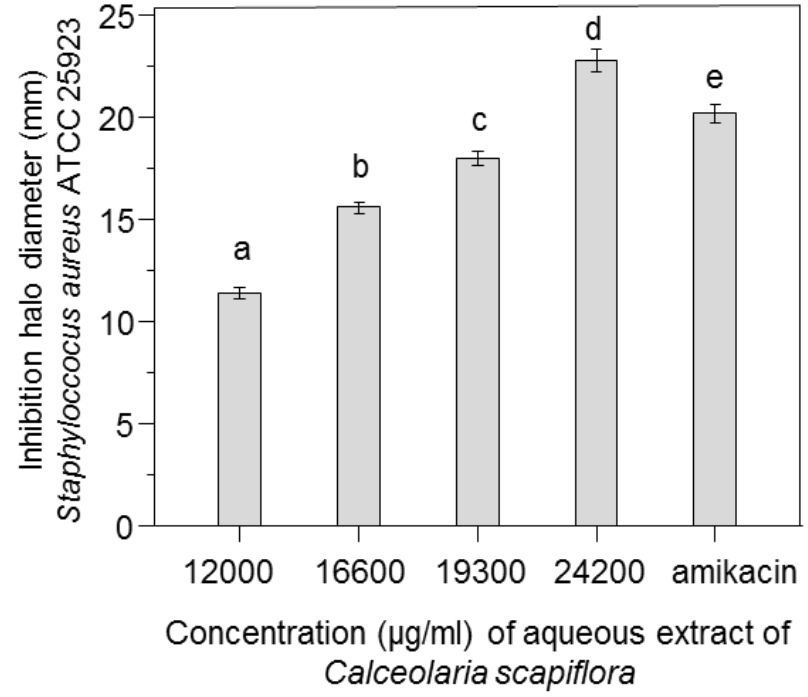

Figura 2. Inhibición de halos de Staphyloccocus aureus ATCC 25923 expuestos a diferentes concentraciones del extracto acuoso de Calceolaria scapiflora y al antibiótico de amplio espectro amikacina. Letras diferentes sobre barras de error indican diferencia significativa $(P<0,05)$ entre los los tratamientos. 
Muchos estudios anteriores han demostrado que estos metabolitos presentan alta actividad antimicrobiana, especialmente contra bacterias gram positivas como $S$. aureus, (Puupponen et al., 2001, Lin et al. 2003, Cushnie \& Lamb, 2005).

Desconocemos la razón del por qué el extracto de $P$. americana var. Fuerte no presento ningún efecto bactericida sobre $S$. aureus y E. coli a pesar de contener metabolitos con actividad antimicrobiano como las lactonas sesquiterpénicas y triterpenos/esteroines, que fueron reportadas con alta actividad bactericida por Katerere et al. (2003), y Lin et al. (2003).

Una probable explicación podría ser la mayor o menor presencia de metabolito específico en el extracto de cada especie de planta. Por ejemplo, encontramos la presencia moderada de flavonoides en el extracto de $C$. scapiflora y traza en $P$. americana. Estudios anteriores mostraron alta actividad bactericida de flavonoides (Puupponen et al., 2001, Cushnie \& Lamb, 2005). El grupo hidroxilo fenólico en la estructura química de los flavonoides facilita penetrar a través de la membrana celular bacteriana causando así la desnaturalización de las proteínas protoplasmáticas (Puupponen et al., 2001). Los flavonoides también pueden inhibir o provocar errores de lectura durante la síntesis de ADN o ARN debido a que presenta una estructura similar al de las bases nitrogenadas de los ácidos nucleicos (Cushnie \& Lamb, 2005). Otra posible explicación puede ser la presencia de un tipo específico del grupo de metabolitos - p.ej. existen más de cinco mil tipos de flavonoides (Ross \& Kasum 2002) - con mayor o menor actividad bactericida. Estos vacíos sugieren de la necesidad de realizar un estudio fitoquímico más detallado para determinar el tipo específico del metabolito para inferir en el uso medicinal específico o farmacológico de estas u otras plantas.

\section{CONCLUSIONES}

Los resultados del presente estudio muestran el potencial uso de $C$. scapiflora como medicina alternativa, representando una fuente valiosa en el tratamiento de agentes infecciosos, particularmente contra bacterias Gram positivas. Reportamos por primera vez la importancia bactericida de la especie andina $C$. scapiflora.

\section{REFERENCIAS BIBLIOGRÁFICAS}

Astete, L.S, Flores, F.F, Buckley D.A, \& Villarreal, M.J. (2004). Sensibilidad antibiótica de los gérmenes causantes de infecciones urinarias en pacientes ambulatorios en el Hospital Nacional Arzobispo Loayza. Rev. Soc. Per. Med. Inter. 17(1)

AOAC. 1990. Official Methods of Analysis. $15^{\text {ta }}$ ed. Association of Official Agricultural Chemistry. Washington, D.C., USA. $500 \mathrm{p}$.

Battilana C. (1997). Infección del tracto urinario: problema común en la práctica médica. Diagnóstico, 36:29-31.

Brack, A. (1999). Diccionario enciclopédico de plantas útiles del Perú. Programa de las Naciones Unidas para el Desarrollo, Centro Bartolomé de las Casas, Cuzco.

Carballo, J.L., Hernández-Inda, Z.L., Pérez, P., \& GarcíaGrávalos, M.D. (2002). A comparison between two brine shrimp assays to detect in vitro cytotoxicity in marine natural products. BMC biotechnology, 2 (1), 17.

Cotillo, P. (1990). Métodos farmacológicos en investigación de productos vegetales.
Cushnie, T.T., \& Lamb, A.J. (2005). Antimicrobial activity of flavonoids. International journal of antimicrobial agents, 26(5), 343-356.

Evans, W. (1984). Farmacognosia, 1984, 30 Impresión. México D.F. Editorial Continental, S.A. de C.V. págs.88, 104, 173-175.

FAOSTAT (2014) Crops - Statistical Databases. Disponible en: http://www.fao.org/faostat/en/\#data/QC (acceso 13 julio 2017).

Farnsworth, N. R., Akerele, O., Bingel, A.S., Soejarto, D.D., \& Guo, Z. (1985). Medicinal plants in therapy. Bulletin of the world health organization, 63(6), 965.

Gualdron, V.R \& Lopez, P.S. (1994). Estudio fitoquímico prelimmar y letalidad sobre larvas de Artemia Salina de algunas plantas superiores colombianas. Tesis. Universidad Nacional de Colombia. Departamento de Farmacia.

Huamantupa, I., Cuba, M., Urrunaga, R., Paz, E., Ananya, N., Callalli, M, Pallqui, N \& Coasac, H. (2011). Riqueza, uso y origen de plantas medicinales expendidas en los mercados de la ciudad del Cusco. Revista Peruana de Biología, 18 (3) 283.

Jiménez, M.M \& Lazo, F.E. (2005). Determinación de taninos en epicarpio de Persea americana g. (aguacate), corteza de Psidium guajava 1. (guayabo) y semillas de Vitis vinifera dc. (Vid). Grado de licenciatura en quimica y farmacia. San Salvador, el salvador, centro América.

Katerere, D.R., Gray, A.I., Nash, R.J. \& Waigh, R.D. (2003). Antimicrobial activity of pentacyclic triterpenes isolated from African Combretaceae. Phytochemistry, 63(1), 81-88.

La Madrid, S.A., Fukuda, F.F., De Meritens, A.B. \& Menchola, J.V. (2004). Sensibilidad antibiótica de los gérmenes causantes de infecciones urinarias en pacientes ambulatorios en el Hospital Nacional Arzobispo Loayza. Rev. Soc. Per Med Inter, $17,5-8$.

Lin, F., Hasegawa, M. \& Kodama, O. (2003). Purification and identification of antimicrobial sesquiterpene lactones from yacon (Smallanthus sonchifolius) leaves. Bioscience, biotechnology, and biochemistry, 67(10), 2154-2159.

Luján. R.D. \& Pajuelo, C.G. (2008). Frecuencia y susceptibilidad antimicrobiana de patógenos aislados en infección del tracto urinario. Universidad Nacional Federico Villarreal, Lima, Perú. Rev Biomed , 19:110-115

Martínez-Flórez, S., González-Gallego, J., Culebras, J. M. \& Tuñón, M. (2002). Los flavonoides: propiedades y acciones antioxidantes. Nutr Hosp, 17(6), 271-278.

McLaughlin, J. L., Chang, C. J., \& Smith, D. L. (1993). Simple bench-top bioassays (brine shrimp and potato discs) for the discovery of plant antitumor compounds: review of recent progress.

Myers, N., Mittermeier, R.A., Mittermeier, C. G., Da Fonseca, G. A., \& Kent, J. (2000). Biodiversity hotspots for conservation priorities. Nature, 403(6772), 853.

Pahua, R.M, Ortiz, M.A, Chamino, G. \& Carduña L. (2007). Estudio de las propiedades de la semilla de Aguacate (Persea americana) variedad Hass para el aprovechamiento integral del fruto.

Parra, A.L., Yhebra, R.S., Sardiñas, I.G., \& Buela, L.I. (2001). Comparative study of the assay of Artemia salina L. and the estimate of the medium lethal dose (LD50 value) in mice, to determine oral acute toxicity of plant extracts. Phytomedicine, 8(5), 395-400.

Puppo, P. (2006). El género Calceolaria (Calceolariaceae) en el departamento de Lima Perú. Revista Peruana de Biología, 13(1), 85-93. 
Puppo, P. (2010). Nuevas distribuciones para 24 especies de Calceolaria (Calceolariaceae) en el Perú y primer registro de Calceolaria perfoliata. Revista Peruana de Biología, 17(2), 155162.

Puupponen-Pimiä, R., Nohynek, L., Meier, C., Kähkönen, M., Heinonen, M., Hopia, A., \& Oksman-Caldentey, K. M. (2001). Antimicrobial properties of phenolic compounds from berries. Journal of applied microbiology, 90(4), 494-507.

Shamsuddin, A. A., Najiah, M., Suvik, A., Azariyah, M. N., Kamaruzzaman, B. Y., Effendy, A. W., \& Akbar John, B. (2013). Antibacterial properties of selected mangrove plants against Vibrio species and its cytotoxicity against artemia salina. World Applied Sciences Journal, 25(2), 333-340.
Roshchin Y.V. \& Gerashchenko G.I. (1973) Anti-inflammatory activity of some flavonoids. Vopr Farm Dal'nem Vostoke 1:135 Ross, J \& Kasum, C. (2002). Dietary Flavonoids Bioavailability, Metabolic effects and safety.Annual Review or nutruitium, 22 (11), 19-34

Saxena, M., Saxena, J., Nema, R., Singh, D. \& Gupta, A. (2013). Phytochemistry of medicinal plants. Journal of Pharmacognosy and Phytochemistry, 1(6).

Presentado: 02/04/2021

Aceptado: 19/06/2021

Publicado: 19/07/2021 